\title{
Aluminum Behavior during Fire Heating: Focus on Deformation
}

\author{
JUSTIN BOWYER ${ }^{1}$, ANAY LUKETA ${ }^{2}$, WALTER GILL ${ }^{2}$, and BURL DONALDSON ${ }^{2}$ \\ ${ }^{1}$ Weapon Product Definition \\ Los Alamos National Laboratory \\ Los Alamos, NM 87545, USA \\ ${ }^{2}$ Fire and Aerosol Sciences \\ Sandia National Laboratories \\ Albuquerque, NM 87185-1135, USA
}

\begin{abstract}
This paper discusses testing and modeling efforts to experimentally determine, and numerically model the behavior of aluminum at incipient melt conditions. More particularly, the role of the oxide layer which develops on the surface of aluminum which is heating in an oxidizing environment has been found to influence deformation. Several configurations where tested composed of aluminum rods at different orientations with regard to standard gravity, and video images were taken to record movement. Modeling with comparable materials shows similar behavior and encourages additional work where some numerical comparisons could be researched further.
\end{abstract}

KEYWORDS: aluminum deformation, metal relocation, creep, modeling.

\section{INTRODUCTION}

Aluminum alloys can frequently be found in structural and some pressure applications where its weight and stiffness are desirable. However, modest fire heating from combustible materials contained within the structure or external to a pressure vessel will weaken the aluminum which can ultimately deform, thereby failing its intended purpose. Insulating the aluminum can forestall deformation for some period of time, depending on the level of insulation, the heat flux from the fire and duration. Because of the unlimited number of configurations and conditions which are possible in accident scenarios, the motive to model behavior under some set of controlled conditions is validated. In other words, if a model can be demonstrated to be descriptive of actual experimental observation, then some level of confidence in the utility of the model can be obtained. Then the model will see its utility in considering the various different scenarios which might be postulated. It is the objective of this paper to consider such an experiment with presentation of a corresponding model and make comparisons between the actual outcome and the prediction. While this effort is not unique to some other studies which will be discussed with the model presentation, the geometries and heating conditions considered here are unique. In all cases, the temperature of the environment into which the aluminum geometry is inserted, will be above the aluminum melt temperature. So while deformation is certain, the configuration of the deformation shape and movement is the unknown.

\section{APPARENT MELTING TEMPERATURE}

Many aluminum-based materials of interest are alloys, and as such present a melt range as opposed to a fixed melt temperature. When heated, an aluminum alloy will begin to separate into the component parts at the solidus temperature with a solid and liquid phase present. As the material is heated further, eventually both components become liquid at the liquidus temperature. At some point in between, it is believed the material will behave as a liquid - this temperature is usually termed the nil-strength temperature or the nilductility temperature.

The device for determining this temperature is the Gleeble. In this device (Fig. 1), a rod of the aluminum material is placed between two water cooled copper jaws and electrical current is passed along the rod. The resultant heating induces a parabolic temperature distribution along the rod that can be precisely controlled and observed with use of a thermocouple in the center of the sample. The rod can be simultaneously loaded in tension or compression which allows the determination of nil-strength failure temperature. Preliminary results with $\mathrm{Al} 6061$ alloy in compression gave a temperature at failure of $640{ }^{\circ} \mathrm{C}$ on two separate runs. A third observation with the rod in tension gave $600{ }^{\circ} \mathrm{C}$ [1]. The solidus for $\mathrm{Al} 6061$ is $582^{\circ} \mathrm{C}$ and the liquidus 
is $652{ }^{\circ} \mathrm{C}$, so either result is plausible. Further investigation to determine the cause of the discrepancy is underway.

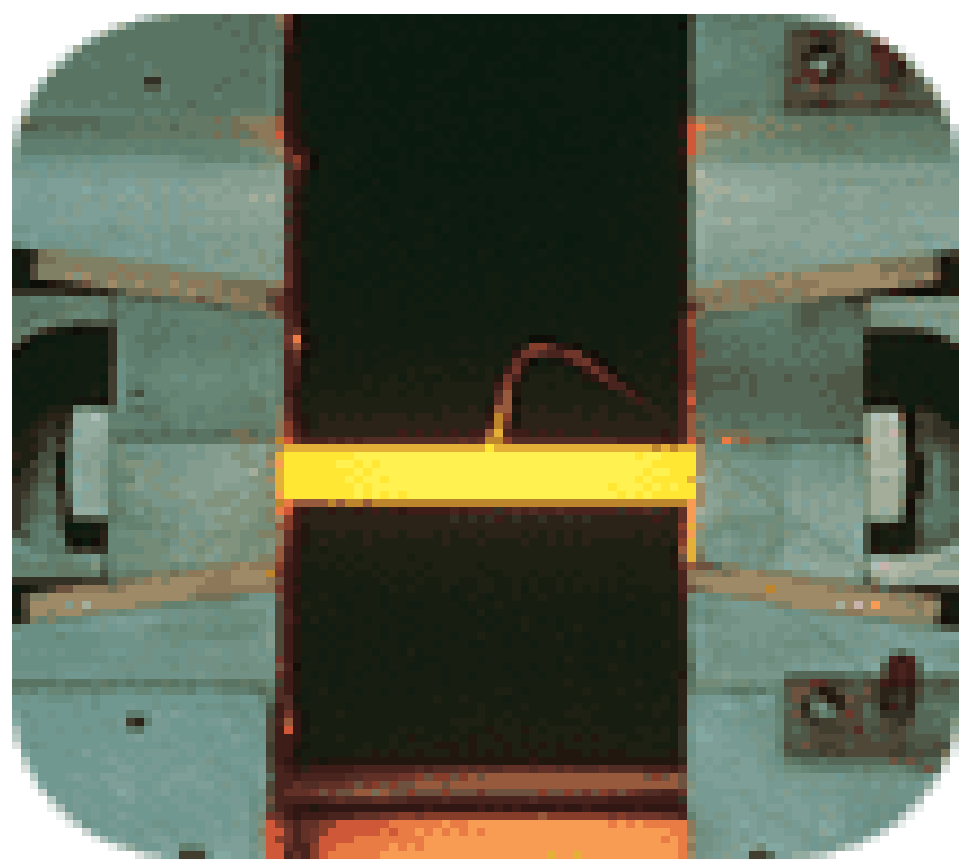

Fig. 1. The Gleeble Heating Device.

\section{THE MELTING FIN EXPERIMENT}

Figure 2 shows various configurations for heating a representative embedded component (in this case, an aluminum rod either 0.125 " $(0.3175 \mathrm{~cm})$ or $0.25 "(.635 \mathrm{~cm})$ diameter). The component is connected to the outside environment via a heat path to an external heat sink. Both the heat path and heat sink are aluminum, and as the aluminum responds to heating, deformation occurs. This can indicate that a generic component time-temperature history may deviate from that which is expected. It would then be obvious that the behavior of the aluminum material will alter the outcome of any thermal race between system components.

The experiment uses an aluminum rod passing through a high temperature oven and behaves as a heated fin. One or both ends of the rod pass thorough the oven wall(s) to a heat sink at the external end. A variety of configurations are possible; the ones presently addressed include both horizontal and vertical orientations. In the horizontal orientations there are clamped-free and clamped-clamped configurations (Figs. 3 and 4). In the vertical configurations, the rods are clamped either above or below (Figs. 5 and 6); with the exception of a free standing rod (not clamped) that melts down onto the oven bottom (Fig. 7).

A review of selected frames for these demonstrations indicates that an oxide layer forms on the heated aluminum rods and inhibits the way in which the fin deforms. That is, breaks on the oxide layer indicate points of bending and until the aluminum melt fails, this oxide layer appears to draw down in correspondence to stretching of the underlying free aluminum.

Following these melt sequences, a macro-image of an aluminum rod which has been oxidized and stretched, is shown (Fig. 8) for the purpose of illustrating the higher oxidation state of the surface aluminum in the darker regions.

\section{Aluminum Alloys of Interest}

Table 1 shows the four current aluminum alloys of interest with a few specific thermal properties that are known. 
Table 1. Alloys of interest with selected properties.

\begin{tabular}{|l|l|c|c|c|c|}
\hline Alloy & Use & $\begin{array}{c}\text { T solidus } \\
\left({ }^{\circ} \mathbf{C}\right)\end{array}$ & $\begin{array}{c}\text { T liquidus } \\
\left({ }^{\circ} \mathbf{C}\right)\end{array}$ & $\begin{array}{c}\text { Density } \\
\left(\mathbf{k g} / \mathbf{m}^{\mathbf{3}}\right)\end{array}$ & $\begin{array}{c}\text { Thermal } \\
\text { conductivity } \\
(\mathbf{W} / \mathbf{m} \cdot \mathbf{K})\end{array}$ \\
\hline 1100 & $\begin{array}{l}\text { Industrial pure } \\
\text { material }\end{array}$ & 643 & 657 & 2710 & 222 \\
\hline 6061 & $\begin{array}{l}\text { Convenient alloy for } \\
\text { experimentation }\end{array}$ & 582 & 652 & 2700 & 154 \\
\hline 7075 & Special applications & 477 & 635 & 2810 & 130 \\
\hline 7079 & Special applications & Unknown & Unknown & 2710 & 125 \\
\hline
\end{tabular}
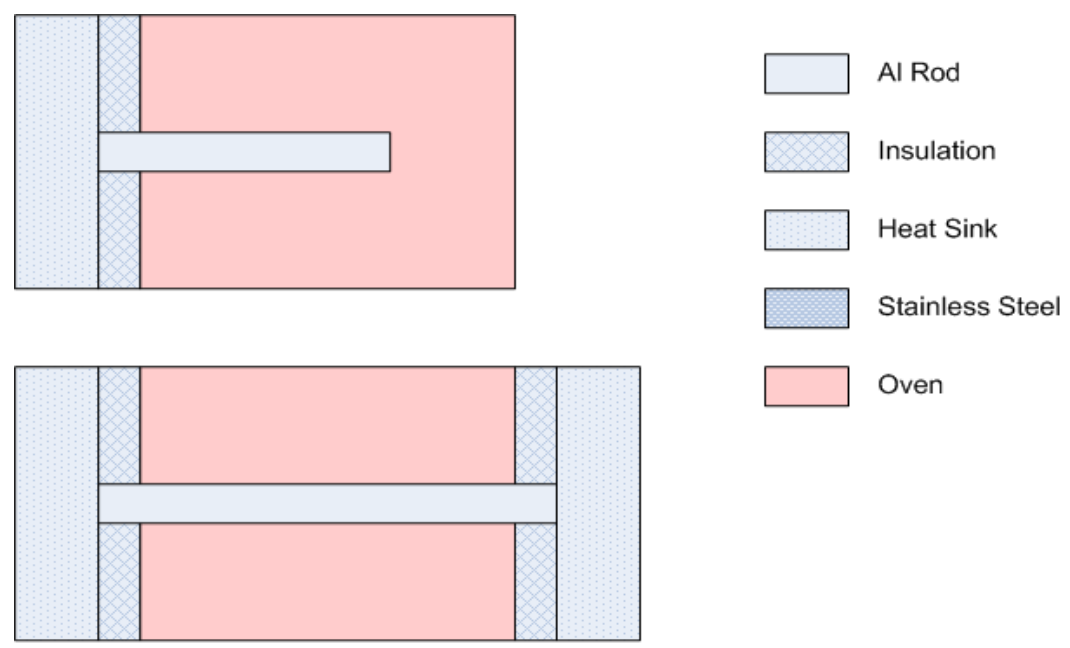

Oven

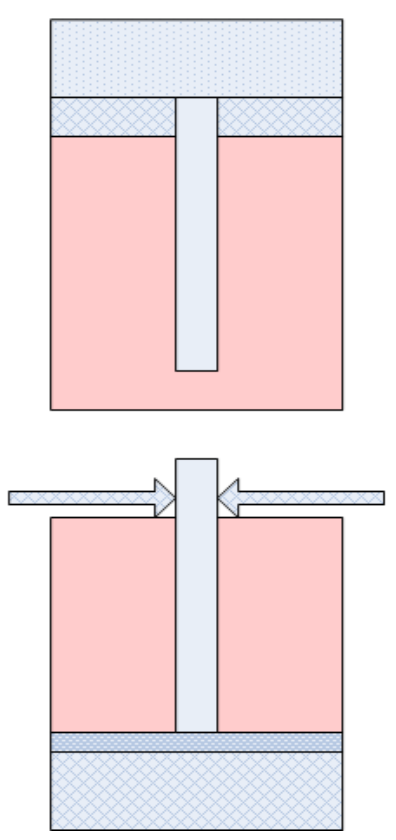

Fig. 2. Various configurations of a representative component, initially cold, when inserted into a high temperature environment. The third figure is inverted in one test, i.e., rod extends vertically from bottom, which corresponds to Fig. 6. 


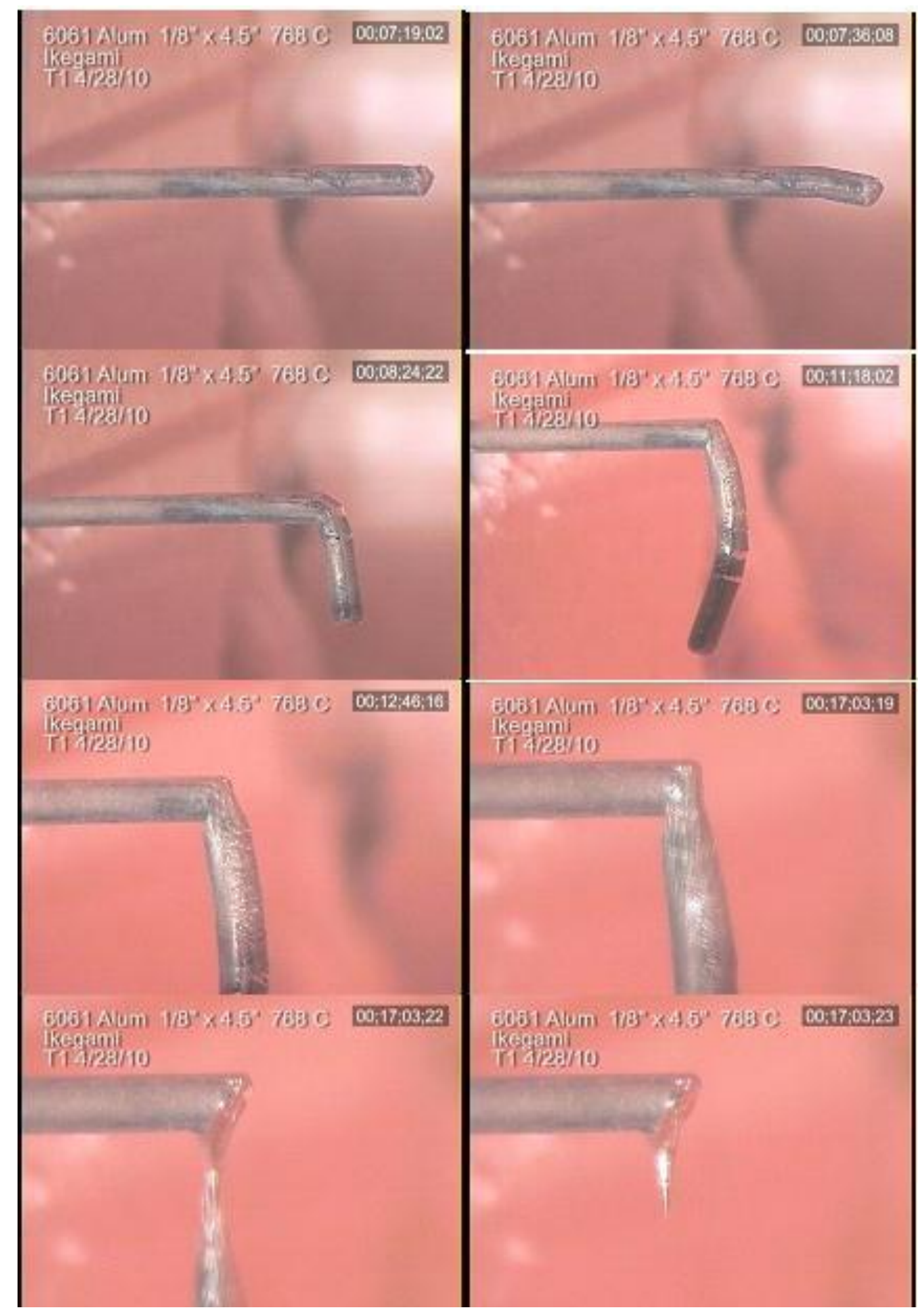

Fig. 3. A cantilevered aluminum rod extending into the furnace. 


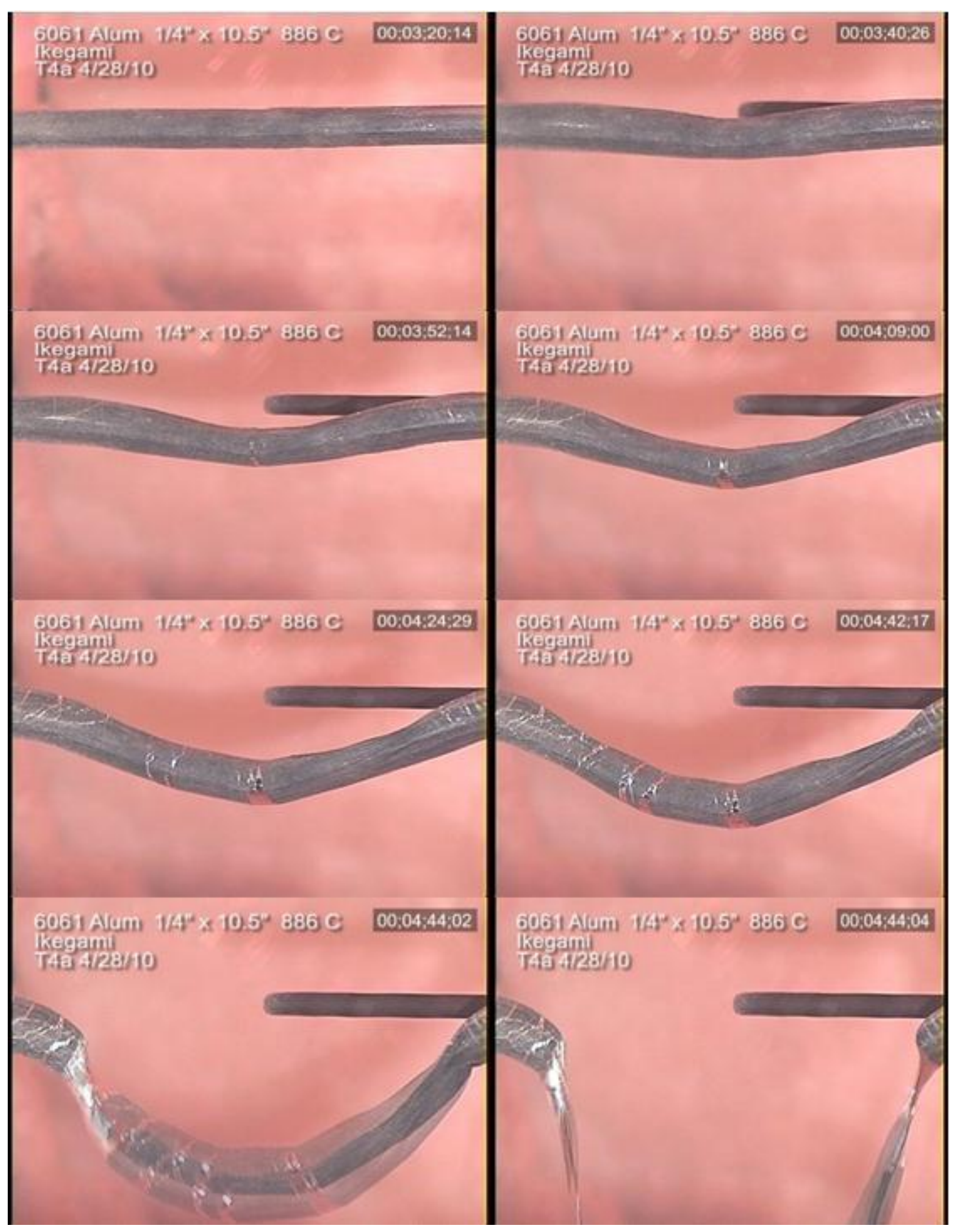

Fig. 4. Simply supported aluminum rod, heated in a furnace at the indicated temperature. Thermocouple appears behind aluminum rod. 


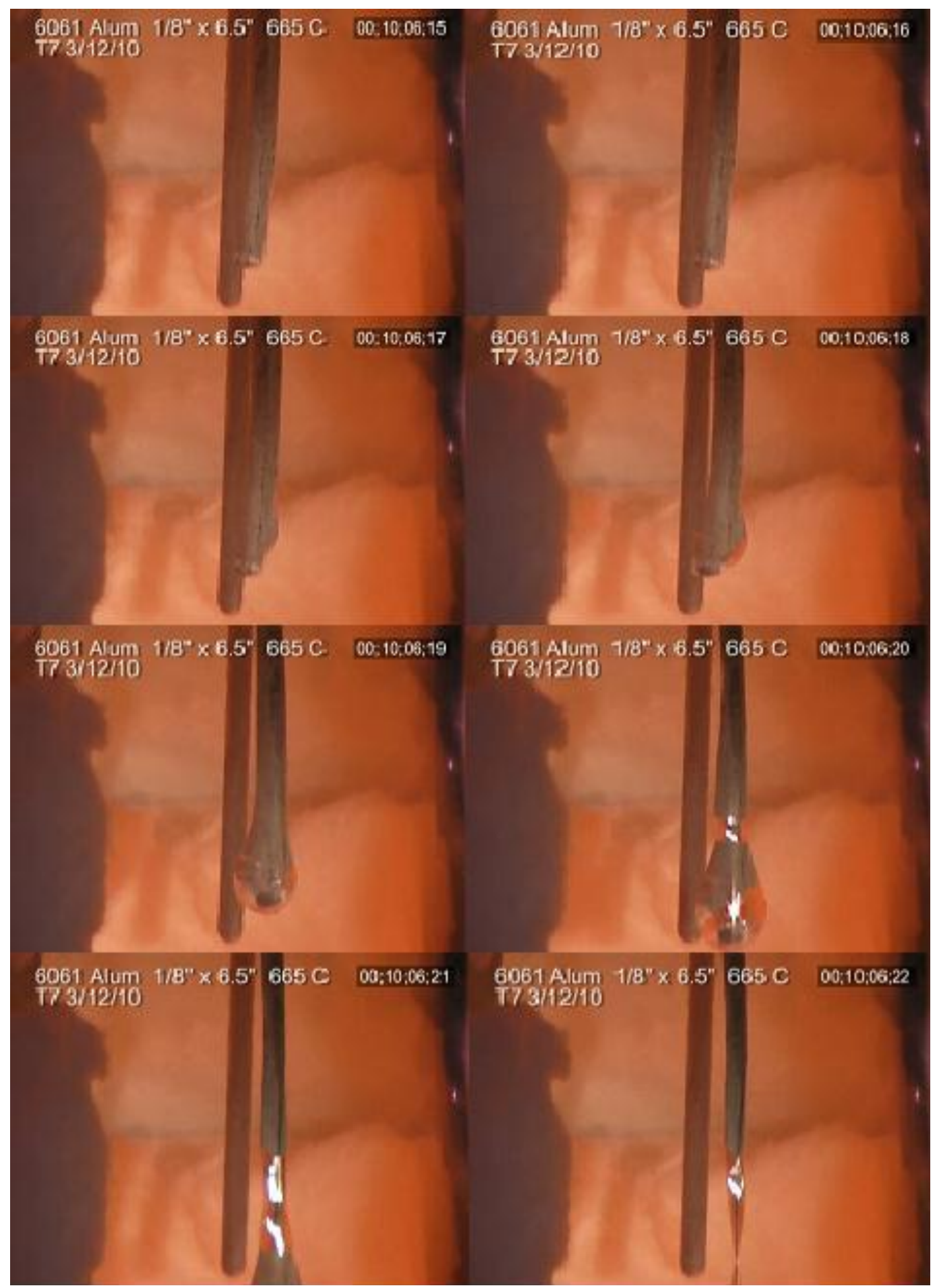

Fig. 5. Aluminum rod inserted into a furnace from above.

Thermocouple appears behind aluminum rod. 


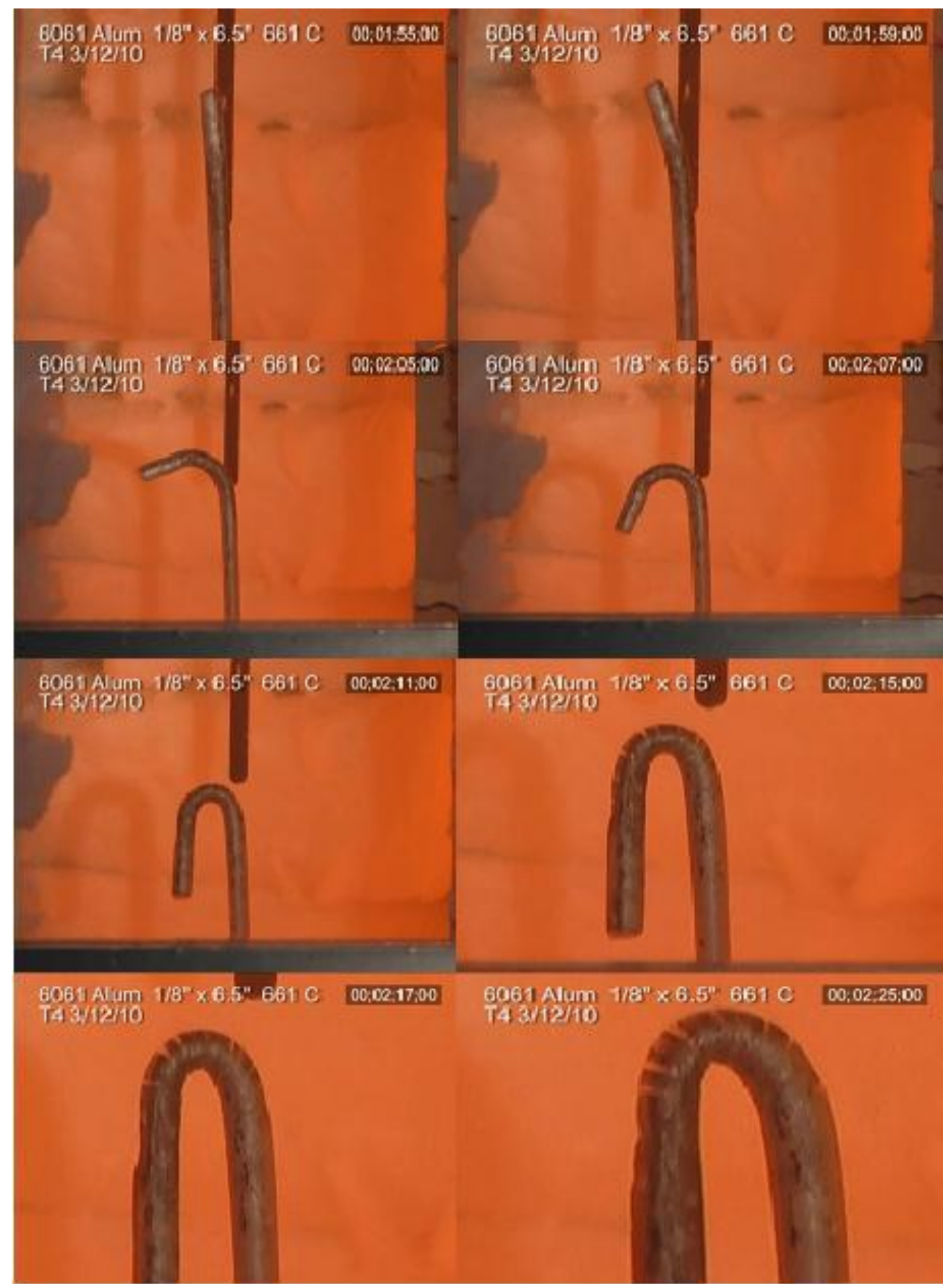

Fig. 6. Aluminum rod extending into furnace from bottom (3 different magnifications). Thermocouple appears behind aluminum rod. 


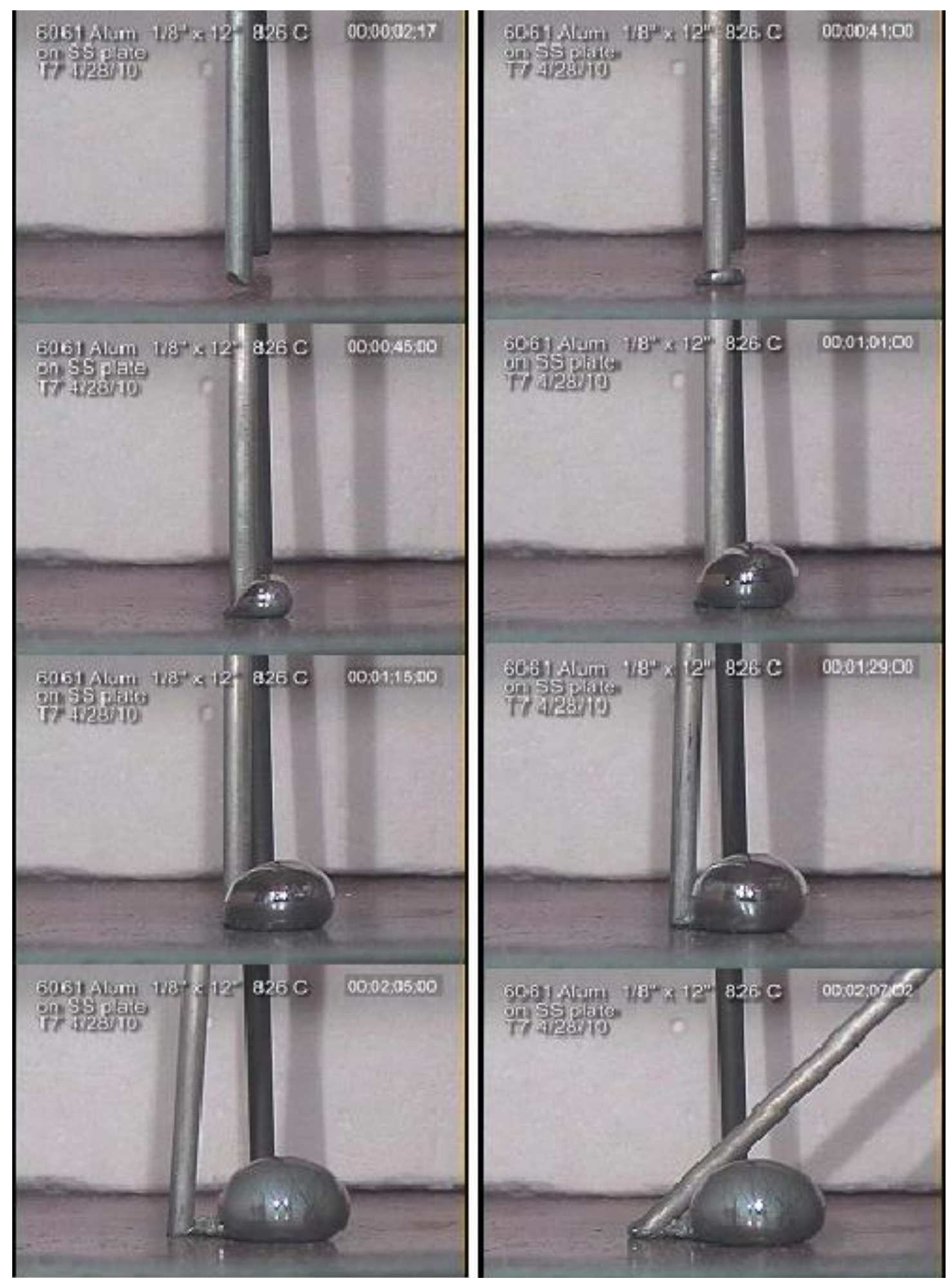

Fig. 7. Unattached aluminum rod with gravity feed, melting onto a stainless steel plate. Darker image is a result of using a filter. Thermocouple appears behind aluminum rod. 


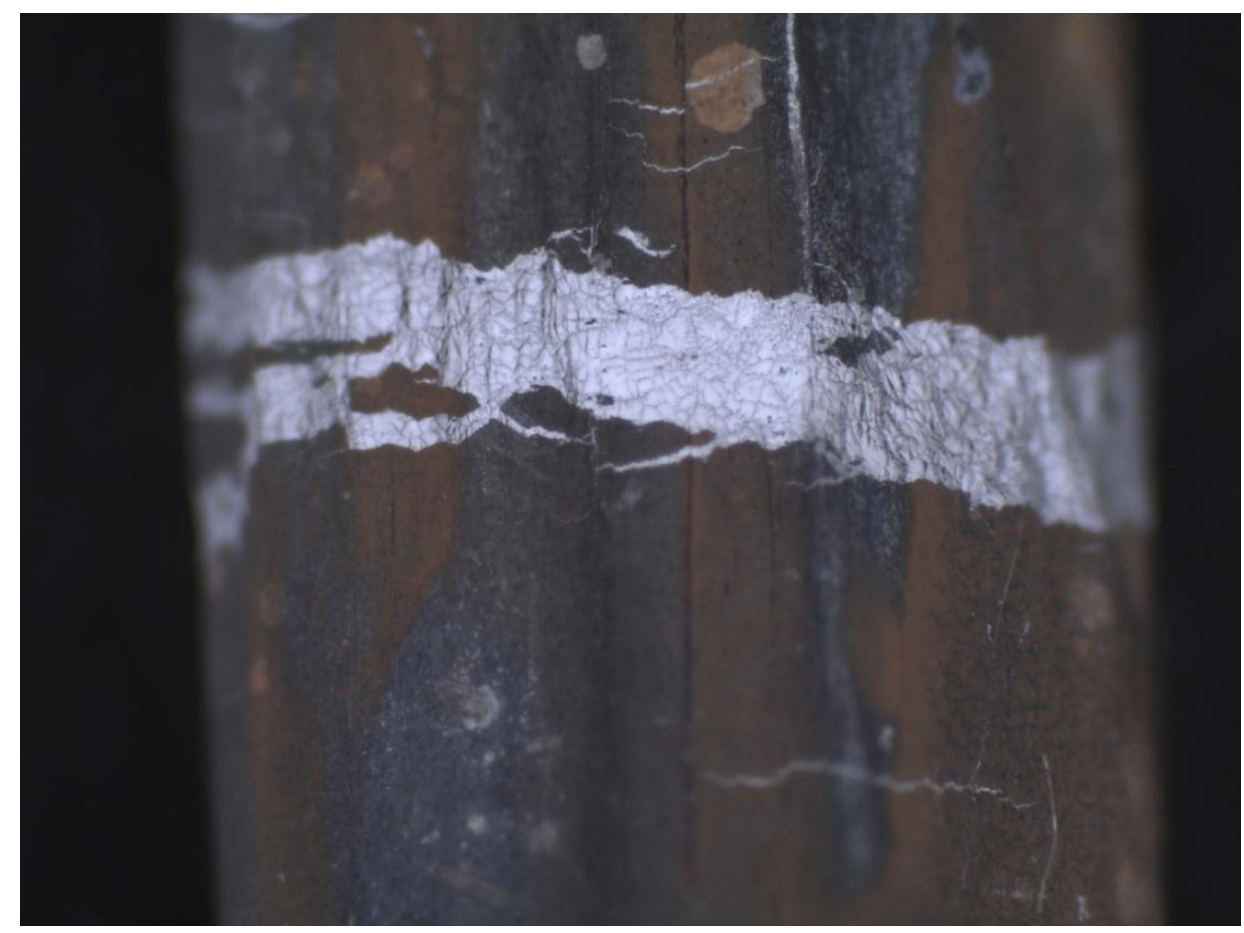

Fig. 8. Macro-image of stretched regions on vertical rod (corresponds to Fig. 6.). Presumably bright regions show lower oxidation where heavier oxide layer has broken; confirmed by SEM/EDS analysis.

\section{MODELING CONSIDERATIONS AND APPROACH}

This section provides discussion of Sandia's computational modeling capabilities regarding aluminum alloys subjected to a high temperature environment sufficient to result in melting and relocation. Some questions to be answered are: 1) Is the aluminum alloy component removed when melted?; 2) Does it behave as a flowing liquid?; 3) How do components deform under various thermal and structural loads and how are heat transfer pathways to adjacent components affected?; 4) Under what conditions does an oxide layer form?; 5) Does the oxide layer affect deformation and heat transfer? The answers to these questions will determine what code and models are appropriate for this application.

It is evident from the exploratory experiments that the specimens displayed creep deformation rather than an abrupt transition from solid to liquid in which the aluminum flows freely. The formation of an oxide layer, also known as alumina, was also observed which continually fractured at high stress points. At these fracture regions un-oxidized or lightly oxidized aluminum could be seen which appeared to behave as a visco-plastic material. These experiments demonstrated that structural components of aluminum alloy behave as a solid undergoing creep deformation when exposed to a high heat flux; that is, there is a permanent time-dependent deformation under exposure to high temperatures and constant applied load.

Creep can be described as occurring over three stages and begins at a temperature around $0.5 T_{m}(473 \mathrm{~K})$ for aluminum where $T_{m}$ is the absolute melting temperature. The stages are identified by the slope of the strain over time with the primary stage having a decreasing slope, secondary stage a constant slope, and tertiary stage an increasing slope. The extent of these stages will vary depending on the material. Typically an empirical approach is used to model these stages by developing equations that fit the experimental data. Creep deformation is a function of material properties, magnitude and duration of applied thermal load, and stress. There are different mechanisms responsible for deformation that occurs at the grain scale for crystalline material that encompasses the categories of dislocation, climb, diffusive flow, and grainboundary sliding [2]. The applicable constitutive equation will depend upon the thermal load, stress, or strain rate. Deformation mechanism maps provide an approximate guide for the stress-temperature states for which these mechanisms operate [3]. An example of such a map is shown in Fig. 9 for aluminum. 


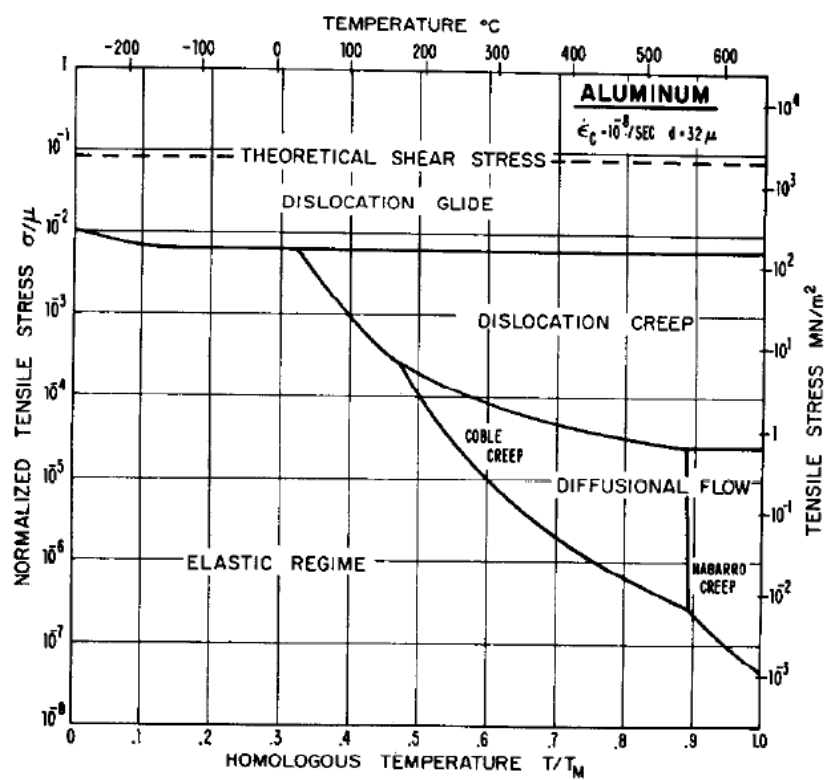

Fig. 9. Deformation mechanism map from Ref. [10].

Different constitutive equations have been shown to fit the data within the dislocation creep region depending upon the level of stress. An equation known as power-law creep is widely used to fit data for low to intermediate stress levels and a constant strain rate within this region. The form is typically

$\dot{\varepsilon}=A \sigma^{n} e^{-Q / R T}$

where $A$ and $n$ are material dependent constants, $T$ is temperature, $R$ is the universal gas constant, and $Q$ is the activation energy. Both $Q$ and $n$ depend on material and temperature. This equation has been widely used to determine the steady-state strain rate during the secondary stage for design purposes. Keep in mind that it spans a limited region of the deformation map and constitutive equations are required to cover other regions. For example, the Johnson-Cook damage model for Al 7075 has been used for high temperature, high stress states [4].

There is a great deal of literature describing the behavior of aluminum and its alloys under various elevated temperature ranges and strain rates [5]. Based upon experimental data, constitutive models for creep deformation have been developed. Since Al-7079 is obsolete, no experimental data on creep parameters have yet been found from a literature search. Al-7079 was developed for aircraft, but due to stress corrosion cracking it was discontinued [6]. Al-7079 is an understudy as a specific material of interest and even though it is not in general use, in the experimental and numerical research conducted, the behavior is mindful of other more 'modern' alloys. There is however, an abundance of literature on Al-7075 concerning creep behavior over various ranges of temperature and stress or strain rates. Yousefian et al. obtained data on Al 7075 at $648 \mathrm{~K}$ under uniaxial, biaxial, and tri-axial stress states [7]. Annealed and overheated specimens of different grain orientation were tested over the stress range of 8 to $30 \mathrm{MPa}$ corresponding to a strain rate range of $10^{-7}$ to $10^{-3}\left(\mathrm{~s}^{-1}\right)$. It was found that the tertiary creep stage is dominant with a very minor secondary creep stage regardless of microstructure or orientation. However, the behavior of strain over time and minimum rupture strain were found to be dependent on microstructure and orientation. Mechanical properties such as Young's modulus and $0.2 \%$ proof stress decrease with temperature. For 5xxx and 6xxx series Al alloys, Kandare et al. [8] normalized these properties with respect to room temperature values and found the data collapsed onto a single curve independent of original mechanical properties, alloy composition and metallurgical properties. However, the curve fits required a fitting constant for the class of alloys tested. This would indicate that in order to obtain appropriate creep and material properties, data should be obtained on the $\mathrm{Al}$ alloys under consideration in the present study.

Additionally, aluminum alloys subjected to heat fluxes representative of a fire have been studied by Kandare et al. [8] and Malijaars et al. [9], who also performed Gleeble experiments using Al-5083-/H111 
and Al-6060-T66 for different heating rates and loads. These materials were selected since they are frequently used in structures and display different behavior at elevated temperatures. It was concluded that steady-state tests in which specimens are subjected to a constant temperature and strain rate with force measured, is not representative of fire conditions. Transient-state tests in which specimens are subjected to an increasing temperature with constant stress, where strain is measured, is more appropriate for fire conditions. Also, for Al-6060-T66 the strength is different depending on the thermal exposure history; that is, whether the specimen is first heated then loaded or heated and loaded directly. The heating rate also affects the strength with low heating rates resulting in lower critical temperatures for failure. Thus, thermal exposure history prior to loading is important to consider. These findings should be taken into consideration when obtaining data for the Al 7075 and 7079 components.

In addition to considering transient heating and thermal exposure effects, the formation of an oxide layer on the outer surface of the aluminum may affect deformation behavior. The skin strength of the oxide layer for various temperatures is around $1 \mathrm{~N} / \mathrm{m}$ for pure $\mathrm{Al}$ and magnesium based $\mathrm{Al}$ alloys [10]. For comparison, the surface tension of a water/air interface is approximately 7 percent of this value. For pure $\mathrm{Al}$, an upper limit on the oxide layer thickness is approximately $100 \AA$ [11]. This would then mean that the energy per unit volume for the layer is $1 \mu \mathrm{Pa}$. Thus, it fractures very easily, but also continually reforms. Note that the melting temperature of $\mathrm{Al}$ oxide is $2345 \mathrm{~K}$, thus melting of the oxide layer is not anticipated under the fire conditions of interest. From the literature reviewed, the approach typically taken is to develop models and obtain data for the gross behavior of aluminum and aluminum alloys. Thus, constitutive models integrate the effect of the oxide layer on the total deformation behavior and the strength of the oxide layer is not treated separately. This possibly may be the best approach in accounting for the effect of the oxide layer for the system under consideration. Further research is required to determine if this is the case. In summary, additional data is needed on material properties of the aluminum alloys of interest at high temperatures $\left(>0.5 T_{m}\right)$. Ideally, samples used for the actual system should be obtained and tested. It may be necessary to develop a constitutive model which will need to be evaluated once the data is obtained.

The Sandia finite element structural mechanics codes, Adagio and Presto, have the capability to model deformation of metals exposed to high temperatures $[12,13]$. They share similar input structure and functionality. The main difference is that Adagio is an implicit time integration code while Presto is explicit which is suitable for long duration events such as those occurring on the order of up to hours. They are both capable of modeling highly deformable surfaces and have a wide array of material models and element types [14]. The nodal-based tet remeshing capability within Presto and Adagio can model highly deformable surfaces which, based upon the experiments, is a required feature for predictive simulations.

Some exploratory simulations were performed using nodal-based tet remeshing in conjunction with the power-law creep model. Figure 10 shows the sequence of deformation of a vertical $1 / 8$ " $(0.3175 \mathrm{~cm})$ diameter aluminum rod with a prescribed temperature distribution. The intent of the simulation was to observe the nodal-based tet remeshing capability; thus the rod was prescribed to have a low yield strength and Young's modulus in order to expedite the simulation. It can be seen that the rod begins to slump over preferentially to one side due to some numerical instability, most likely due to mesh asymmetry. The point at which it slumps over is due to the creep model responding to the much higher temperatures beginning at that region, thereby increasing the strain rate. The rod then starts to elongate to the point where the tip breaks off. The rod then sways and pieces are torn off. This simulation demonstrates the sensitivity of the creep model to temperature and the capability of the nodal-based tet remeshing algorithm to dynamically track highly deformed surfaces. 


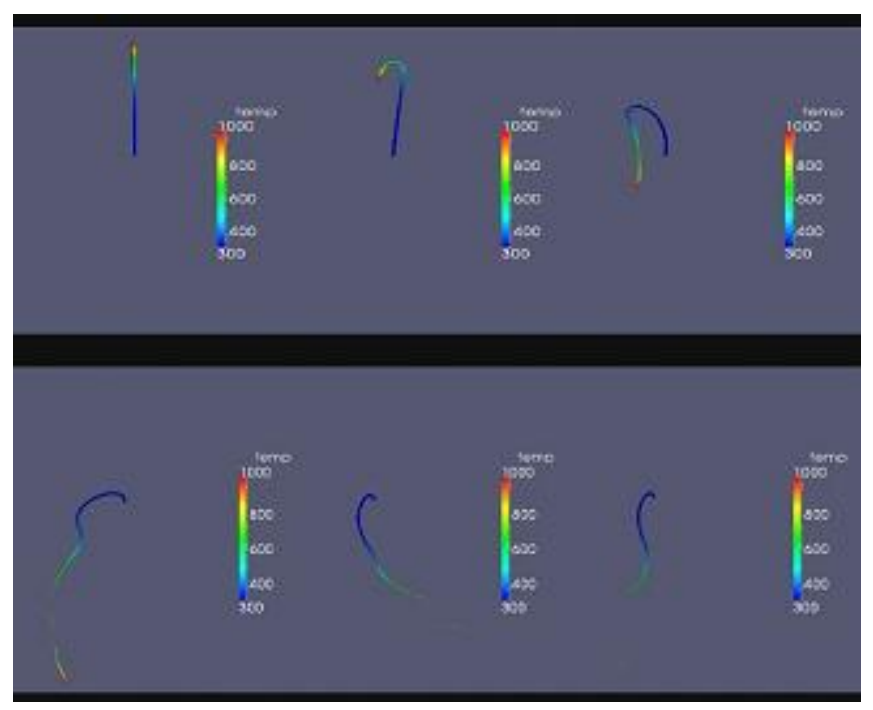

Fig. 10. Presto simulation of creep deformation using nodal-based tet remeshing. Sequence is from left to right.

Presto and Adagio also have the capability of element death which would be useful in modeling fracture. Additionally, different element types can be mixed within a simulation (e.g. Lagrangian particles encased within a sphere comprised of shell elements hitting a block comprised of hex elements). This feature could potentially be useful in modeling the effect of the oxide layer if determined to be significant. The oxide layer could be represented with shell elements that encase the aluminum alloy represented by hex or tet elements. Presto and Adagio can also be coupled to Aria through Arpeggio.

To test this feature, a simulation was performed similar in configuration to the experiments on a $1 / 4$ " $(0.635 \mathrm{~cm})$ diameter aluminum rod placed horizontally within an oven (see Fig. 3 for actual experiment but for a smaller diameter rod). Aria and Adagio were coupled through Arpeggio with the enclosure radiation feature of Aria providing heat transfer to the rod and Adagio provided the deformation. The simulation was performed with prescribed outside wall temperatures equal to the gas-phase temperature measurement obtained from the experiment. The rod was assumed heated to a uniform temperature and the entire length of the rod began to slump. The experiment did not indicate this behavior. The rod rather slumped towards it tip, approximately at $3 / 4^{\text {th }}$ of its length which would indicate that the temperature was higher there. The temperature was measured at only one location in the gas phase in the experiments. Thus, the heat flux from the walls to the rod is uncertain and hence the temperature distribution in the rod is unknown. To determine if a non-uniform temperature distribution affected the deformation an additional exploratory simulation using the power-law creep model was performed in which a rod was prescribed an increasing temperature distribution along its length. The results shown in Fig. 11 indicate that deformation occurs at the location of increased temperature. Thus, the rod in the experiment may not have had a uniform temperature. 

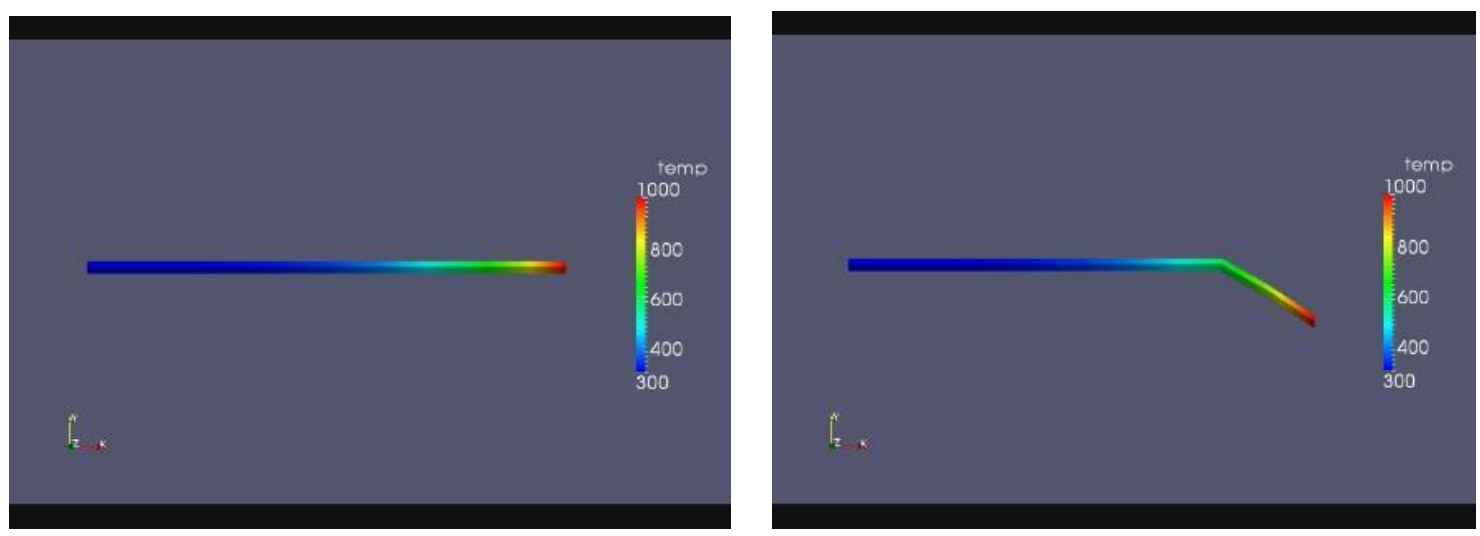

Fig. 11. Presto simulation using power-law creep model; 1/4" $(0.635 \mathrm{~cm})$ aluminum rod with prescribed temperature.

A simulation with different outside wall temperatures surrounding the oven was performed in order to examine results in a non-uniform temperature distribution. The outside wall to the far right of the cross section shown in Fig. 12 was specified at $1000 \mathrm{~K}$ and the remaining walls at $700 \mathrm{~K}$. The simulation was performed on 64 processors. For $50 \mathrm{~min}$ of real time, it took 5 days of computational run time. Note that a more optimum time step may have significantly reduced the simulation time; however, this was not fully explored for this simulation.

For the actual experiment, the rod passes through 1" $(2.54 \mathrm{~cm})$ of insulation and the region at $294 \mathrm{~K}$ is a solid block of aluminum that acts as a heat sink. The walls surrounding the aluminum block and insulation have convective boundary conditions. The results at $50 \mathrm{~min}$ indicate that the rod has a non-uniform temperature distribution of about $350 \mathrm{~K}$ at the attached end and $450 \mathrm{~K}$ at its tip, but the gradient is not sufficient to result in the high degree of deformation near the end of the rod. Additional data on initial and boundary conditions is necessary to compare this simulation to the experiment; otherwise, it's very difficult to reverse-work the problem. The important feature to note from this simulation is the successful coupling between Aria and Adagio using the enclosure radiation model and power-law creep model. This coupling is necessary to capture the feedback between the heat transfer and deformation in the full mock up system.

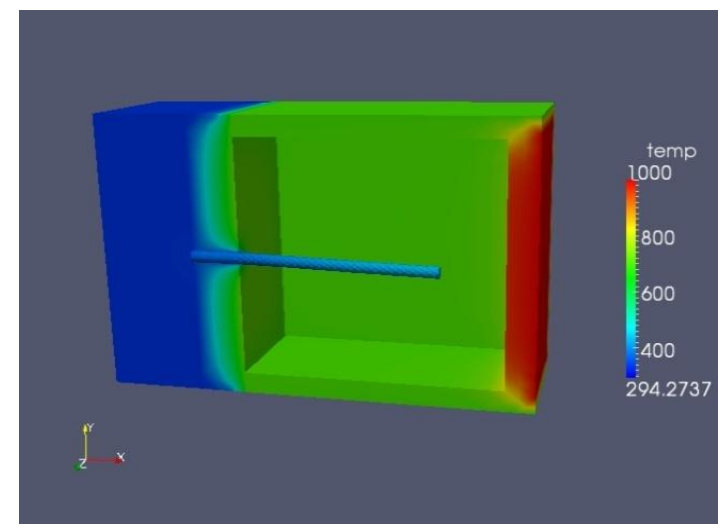

Fig. 12. Arpeggio simulation coupling Adagio and Aria; $1 / 4 "(0.635 \mathrm{~cm})$ aluminum rod in oven.

\section{CLOSURE}

It is important to understand that Aluminum alloys do not just melt. There is structural integrity, although weak, in a wide range before any sort of liquefaction occurs. This behavior is important when one is designing aluminum containment structures that could be exposed to high temperature environments. Based on the preliminary work to date, it appears to be promising that creep models can provide a reasonable match to experimental results. Obviously, much more extensive effort will need to be devoted to fully exploring this capability. 


\section{AKNOWLEDGEMENTS}

Sandia is a multi-program laboratory operated by Sandia Corporation, a Lockheed Martin Company, for the United States Department of Energy's National Nuclear Security Administration under contract DEAC0494AL85000.

\section{REFERENCES}

[1] Knorovsky, G., Personal communication, Experiment and analysis conducted at Sandia National Laboratory.

[2] Dieter, G.E., Mechanical Metallurgy (3 $3^{\text {rd }}$ ed.). New York: McGraw-Hill, 1986. pp. 445-449. ISBN 0-07-016893-8.

[3] Ashby, M., (1972) A First Report on Deformation-Mechanism Maps, Acta Metallurgica 20(7): 887-897, http://dx.doi.org/10.1016/0001-6160(72)90082-X

[4] Brar, N.S., Joshi, V.S., and Harris, B.W., Constitutive Model Constants for Al7075-T651 and Al7075-T6, 2009. $16^{\text {th }}$ APS Topical Conference on Shock Compression of Condensed Matter, pp. 945-948.

[5] Nabarro, F., (2006) Creep in Commercially Pure Metals, Acta Materialia 54(2): 263-295, http://dx.doi.org/10.1016/j.actamat.2005.08.021

[6] Starke, E., (1996) Application of Modern Aluminum Alloys to Aircraft, Progress in Aerospace Sciences 32(2-3): 131-172, http://dx.doi.org/10.1016/0376-0421(95)00004-6

[7] Yousefiani, A., Mohamed, F.A. and Earthman, J.C., Creep Rupture Mechanicsm in Annealed and Overheated $7075 \mathrm{Al}$ under Multiaxial Stress States, 2000. Metallurgical and Materials Trans. A, Vol. 31A, pp. 2807-2821, http://dx.doi.org/10.1007/BF02830340

[8] Kandare, E., Feih, S., Kootsookos, A., Mathys, Z., Lattimer, B., and Mouritz, A., (2010) CreepBased Life Prediction Modelling of Aluminium in Fire, Materials Science and Engineering: A 527(4-5): 1185-1193. http://dx.doi.org/10.1016/j.msea.2009.10.010

[9] Maljaars, J., Soetens, F., and Katgerman, L., (2008) Constitutive Model for Aluminum Alloys Exposed to Fire Conditions, Metallurgical and Materials Transactions A 39(4): 778-789, http://dx.doi.org/10.1007/s11661-008-9470-0

[10] Syvertsen, M., (2006) Oxide Skin Strength on Molten Aluminum, Metallurgical and Materials Transactions B 37(3): 495-504. http://dx.doi.org/10.1007/s11663-006-0033-8

[11] Strohmeier, B., (1990) An ESCA Method for Determining the Oxide Thickness on Aluminum Alloys, Surface and Interface Analysis 15(1): 51-56, http://dx.doi.org/10.1002/sia.740150109

[12] Adagio 4.16 User's Guide, SAND report. May 2010. SAND2010-3111.

[13] Presto 4.16 User's Guide, SAND report. May 2010. SAND2010-3112.

[14] Scherzinger, W.M. and Hammerand, D.C., Constitutive Models in LAME, SAND report, SAND2007-5873, September 2007 